\title{
Mass Spectrometric and Gas Chromatographic Evidence for Some New Components in the Gas Phase of Tobacco Smoke*
}

by

K. D. Bartle, School of Chemistry, University of Leeds, England

and

M. Novotný, Chemistry Department, University of Houston, Texas, USA

\section{INTRODUCTION}

The wide variety of chemical type and the large number of compounds present in the gas phase of tobacco smoke make the analysis of this material difficult. Moreover, if studies of the composition are to be correlated with physiological activity, the analysis should be rapid, and contact with metal or the condensed phase should be avoided $(1,2)$. Condensation of the gas phase drawn from a burning cigarette onto an efficient glass open-tubular gas chromatography column at low temperature via a glass injection system followed by temperature programming meets many of the above requirements, but yields only nanogram quantities of individual compounds so that mass spectrometry is the only method of interest for identification purposes. Efficient coupling of the column and mass spectrometer is required if the resolution of the column is to be fully utilised.
We have recently described a technique for the analysis of fresh tobacco smoke by combination open-tubular column gas chromatography/mass spectrometry (3). In this paper we discuss the application of this method in the identification of some new components of tobacco smoke.

\section{EXPERIMENTAL}

The gas phase of fresh smoke from American blend cigarettes without filter tips was injected onto a $120 \mathrm{~m}$ long SF-96 silicone oil-coated glass open-tubular column maintained at $-70^{\circ} \mathrm{C}$ and coupled to an L.KB 9000 mass spectrometer through the low dead volume molecule separator (4). The apparatus has been fully described elsewhere (3). $70 \mathrm{eV}$ mass spectra of components eluted on temperature programming were recorded as described previously $(3,5)$. Figure 1 shows the total ion current monitor chromatogram.

Figure 1. Total ion current chromatogram of $5 \mathrm{ml}$ tobacco smoke split approximately $1: 1$.

Column $120 \mathrm{~m} \times 0.2 \mathrm{~mm}$ I.D. glass open tubular coated with SF-96. Peak numbers refer to text and to Figures $2-7$.

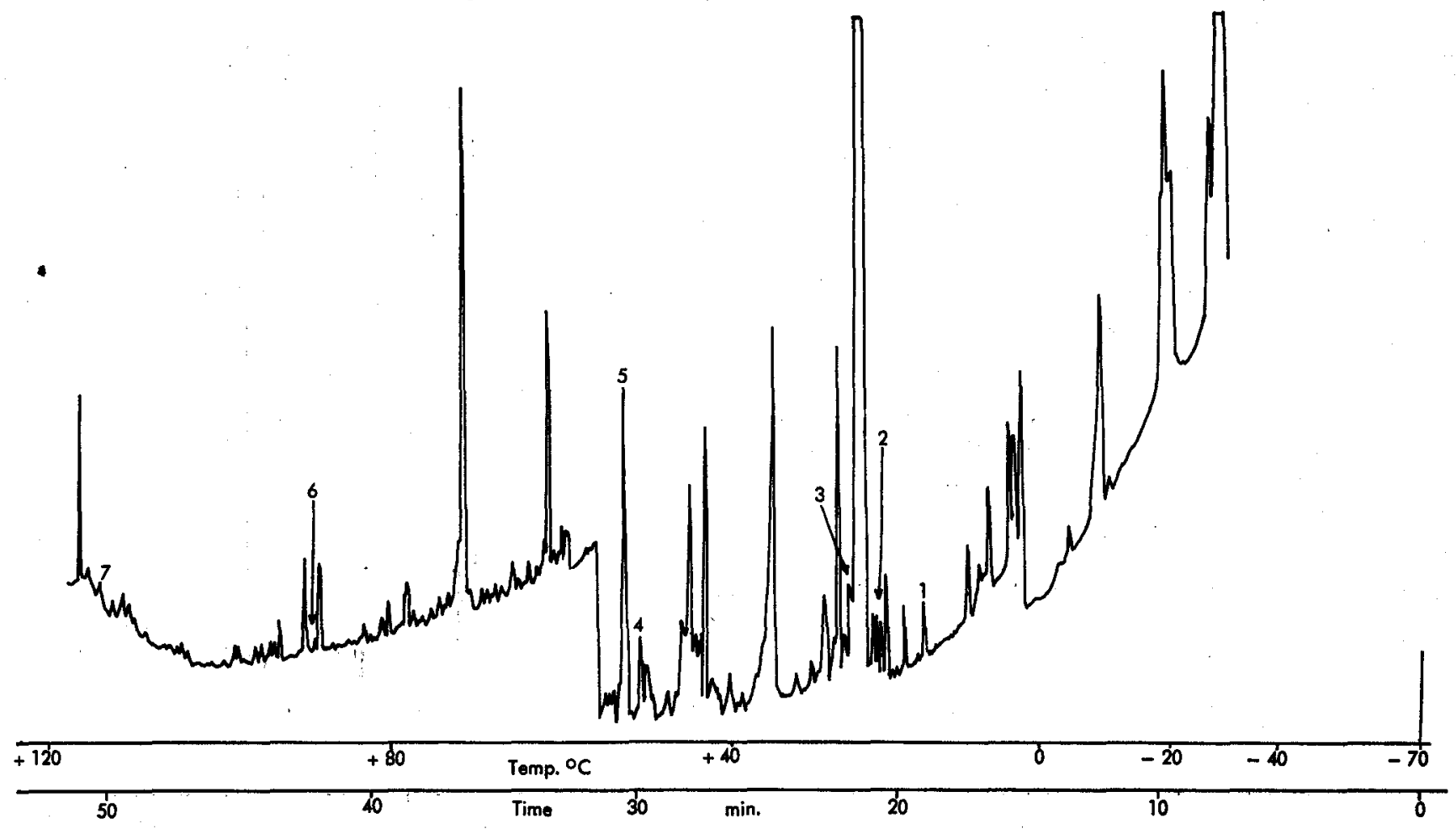

* Received for publication: 11th May, 1970. 
Figure 2. Mass spectra of 1,1-dimethyleyclopropane.

Upper: peak 1 in chromatogram (Figure 1); lower: roforence 6, len most intense peaks.

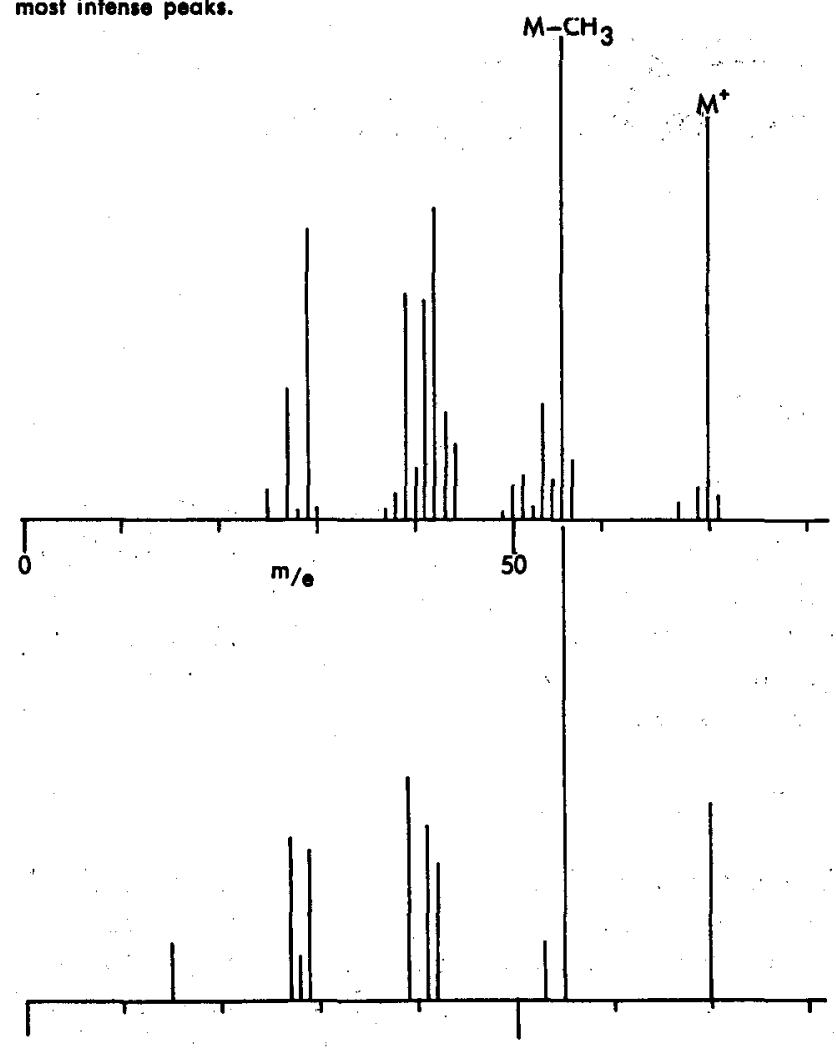

\section{RESULTS AND DISCUSSION}

Components of tobacco smoke identified by comparison of their mass spectra with a literature compilation (6) corresponded in many cases to those previously isolated (see Table I of reference 3) although some compounds e.g. a cresol and a xylenol have not been identified before in fresh smoke, but only after separation of appropriate fractions of smoke condensate. A number of compounds have not, apparently, been recognised in any previous study:

\section{I Cyclopropanes}

The presence of cycloalkanes in tobacco smoke is well known; cyclopentane (7-11), methylcyclopentane ( 7 , $12)$ and cyclohexane $(1,11-14)$ have been identified. While no three-membered ring compounds have previously been detected, they might be expected since the pyrolysis of a number of simple olefins, well known in tobacco smoke, has been shown $(31,32)$ to yield cyclopropanes as a result of primary reactions.

Figures 2-4 show the mass spectra of peaks 1,2 and 3 in the smoke chromatogram; close correspondence with the three possible dimethylcyclopropanes is evident. Peak 3 also contains carbon disulphide. Structural correlations in the mass spectra of cycloalkanes are obtained only with difficulty (15), but all three show the strong molecular ion peak $(\mathrm{m} / \mathrm{e} \mathbf{7 0})$ often found for alicyclic compounds (16) and have $\mathrm{M}-\mathrm{CH}_{3}(\mathrm{~m} / \mathrm{e} \mathrm{55)}$ as the base peak. The separation principle of the silicone oil stationary phase used in this work is volatility, so that simple
Figure 3. Mass spoctra of 1,2-irans dimethyleyclopropana. Upper: peak 2 in chromatogram (Figure 1); lower: reference 6, ten most intense peaks.

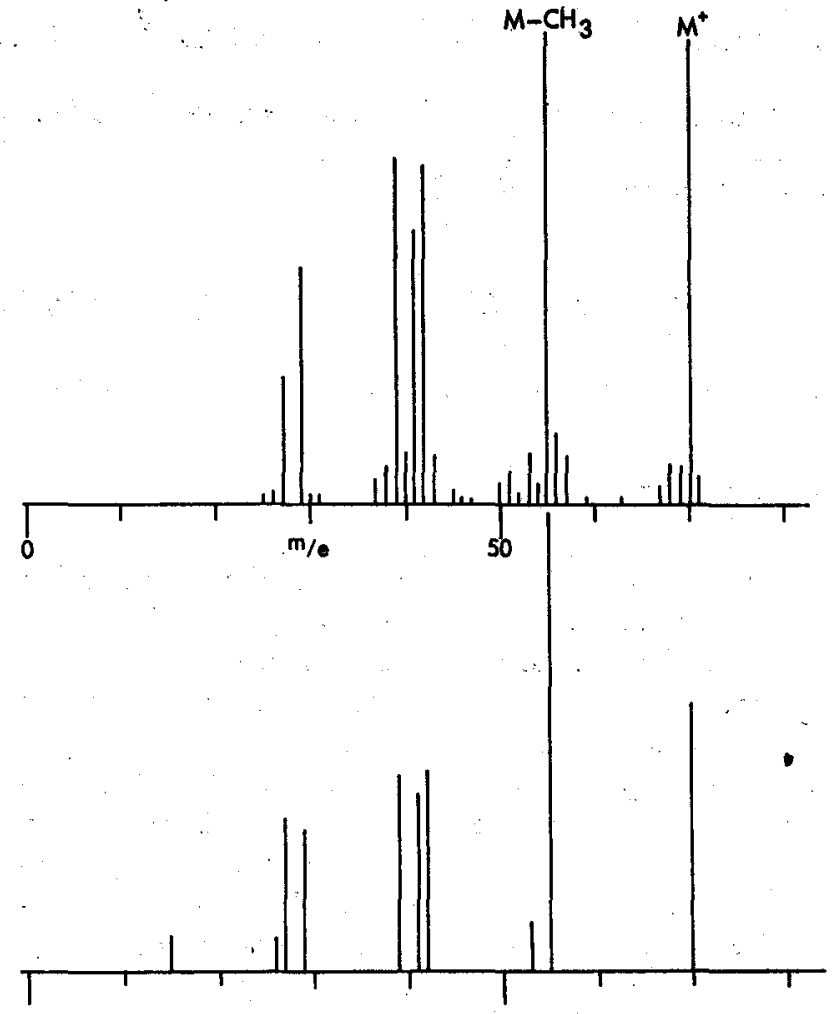

Figure 4. Mass spectra of 1,2-cis dimethyleyelopropane + carbon disulphide.

Upper: peak 3 in chromatogram (Figure 1); lower: reference 6, ten most intenso peaks - carbon disulphido peaks dotted.

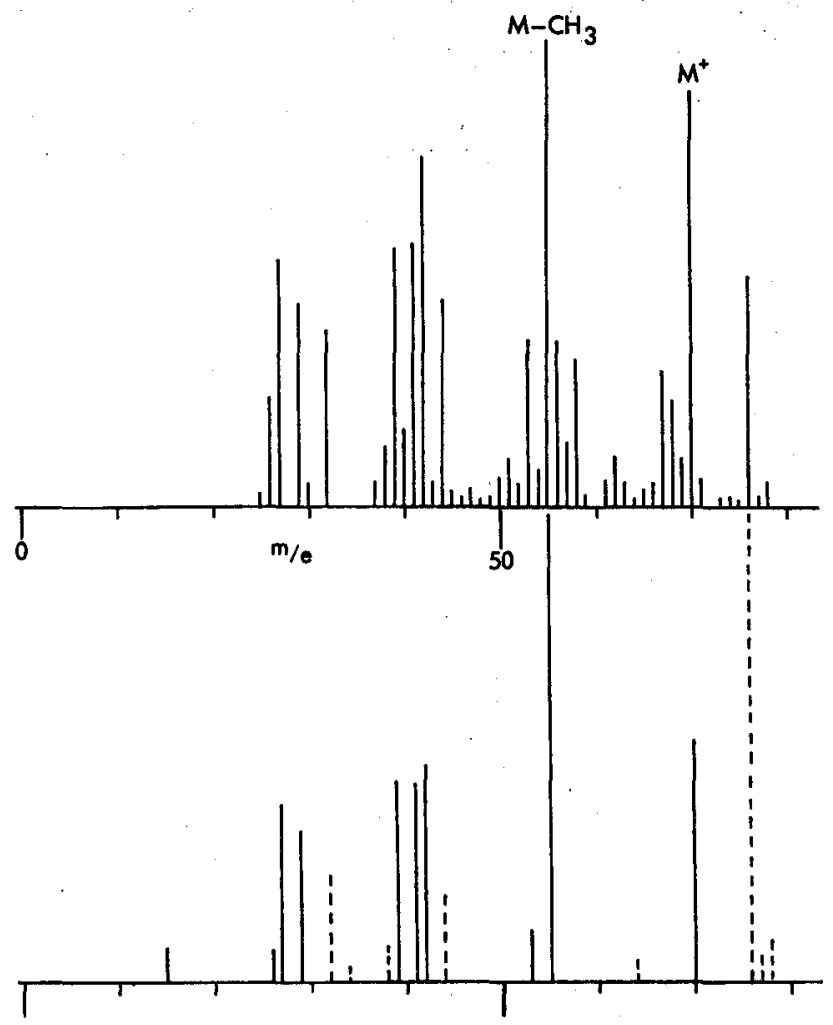

consideration of boiling points allows attribution of peak $I$ to 1,1 -dimethylcyclopropane and peaks 2 and 3 to the trans and cis 1,2 isomers respectively. 
Figure 5. Mass spectirum of 1-chloro-5-methylhexane, peak 7 in chromatogram (Figure 1).

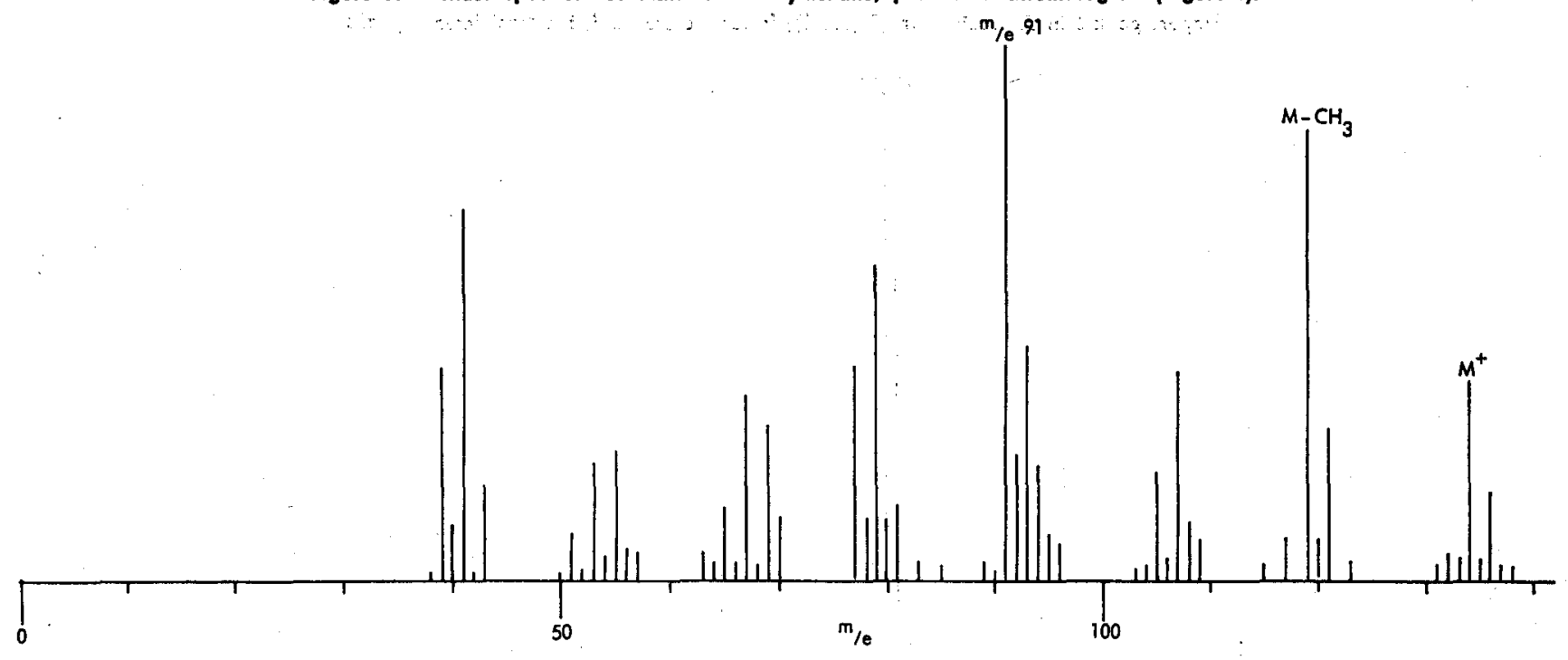

\subsection{1-Chloro-5-methylhexane}

Chlorinated alkanes other than chloromethane $(8,17$, $18,19)$ and possibly chloroethane (17) have not been detected in tobacco smoke. Only small $(\leqslant 30 \%)$ transference of chlorinated agricultural chemicals from tobacco leaf to smoke has been found (20) and gas chromatography/mass spectrometry has been suggested to identify possible pyrolytic products of pesticide residues (21). The characteristic approximately $3: 1$ distribution of the isotopes $\mathrm{Cl}^{35}$ and $\mathrm{Cl}^{37}$ makes the presence of this element in a compound evident from the mass spectrum (Figure 5). Peak 7 in the smoke chromatogram is, therefore, a chloroalkane $\mathrm{C}_{7} \mathrm{H}_{15} \mathrm{Cl}$ with $\mathrm{M}^{+}$ion at $\mathrm{m} / \mathrm{e} 134$. Now the fragment ion $\mathrm{C}_{4} \mathrm{H}_{8} \mathrm{Cl}+(\mathrm{m} / \mathrm{eg})$ is outstandingly prominent in the spectra of $n$-alkylchlorides from hexyl to octadecyl (22), while ions resulting from the loss of $\mathrm{Cl}$ or $\mathrm{HCl}$ are much less probable (23). The base peak in the spectrum of peak 7 has $\mathrm{m} / \mathrm{e} 91$ so that either<smiles>[CH2]CCC=CC1[CH]CC[CH]1</smiles>

1-chloroheptane or 1-chloro-5-methylhexane corresponding to the ion $I$ is indicated. Differentiation of these two is possible by taking into account the high intensity of the $\mathrm{M}-\mathrm{CH}_{3}$ ion at $\mathrm{m} / \mathrm{e} 119$ which seems unlikely unless the compound contains a methyl side chain. In fact, the spectrum (6) of 1-chloroheptane shows only a very weak $\mathrm{m} / \mathrm{e} 119$ peak, and we assign the chloroheptane isomer of tobacco smoke as 1-chloro-5-methylhexane.

\subsection{Olefins}

Grob $(17,24)$ reported the presence of two $\mathrm{C}_{6} \mathrm{H}_{8}$ isomers in tobacco smoke. The mass spectrum (Fig. 6) of peak 4 in our chromatogram corresponds to $\mathrm{C}_{6} \mathrm{H}_{8}$ but is in- distinguishable from those of $1,3,5$-hexatriene [boiling point $\left.(25,26) 78.5^{\circ} \mathrm{C}\right], 1,3$-cyclohexadiene $\left(80.5^{\circ} \mathrm{C}\right)$ $(25,26)$ and 5 -methyl-1,3-cyclopentadiene $\left(73^{\circ} \mathrm{C}\right)(25)$ and is also similar to that of 1,4-cyclohexadiene $\left(86-87^{\circ} \mathrm{C}\right)(25,26)$. Now peak 4 is eluted immediately before benzene [peak 5 - boiling point $(25,26) 80 . x^{\circ} \mathrm{C}$ ] and interpolation in a (linear) graph of retention time, measured from the chromatogram, against boiling point for readily identifiable substances suggests that the unknown has boiling point $78^{\circ} \mathrm{C} ; 1,3,5$-hexatriene is thus strongly suggested. Identification of this highly reactive compound (27) in this analysis in contrast to numerous other studies may be due to the direct injection of smoke onto the gas chromatography column without an intermediate concentration step.

Inspection of lists of the series of alkenes identified in the gas phase of tobacco smoke reveals many in the

Figure 6. Mass spectra of 1,3,5-hoxatriene.

Upper: peak 4 in chromatogram (Figure 1); lower: reference 6, ten most intense peaks.

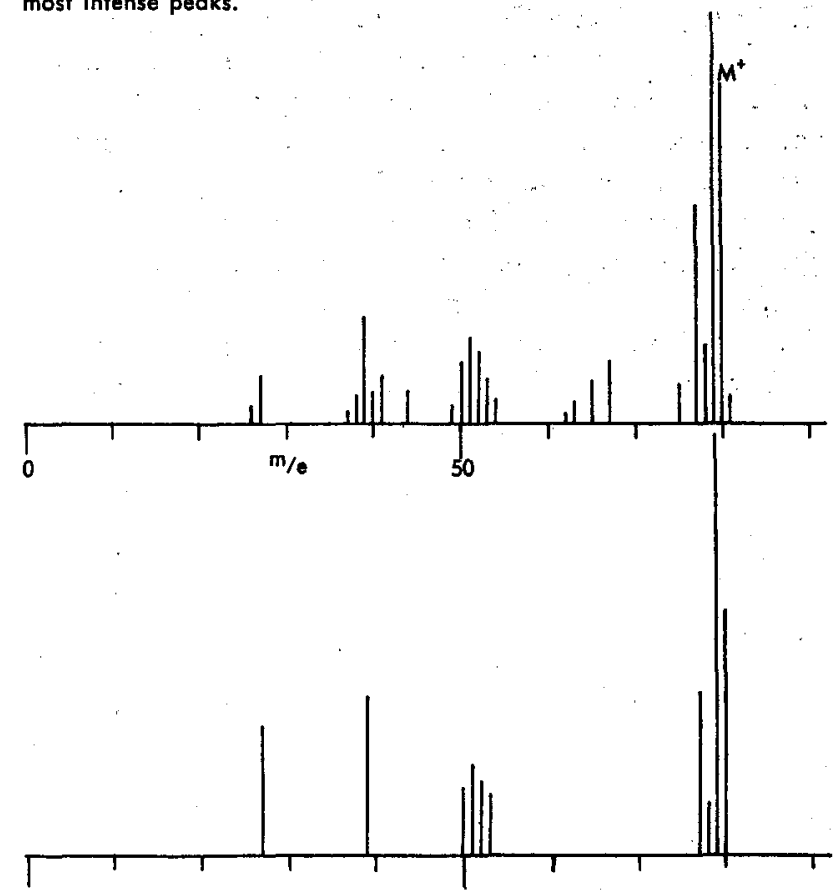


Figure 7. Mass speetra of 2-mothyl-1-octene.

Upper: peak 6 in chromatogram (Figure 1); lower: reforence 6, ten most intense peaks.

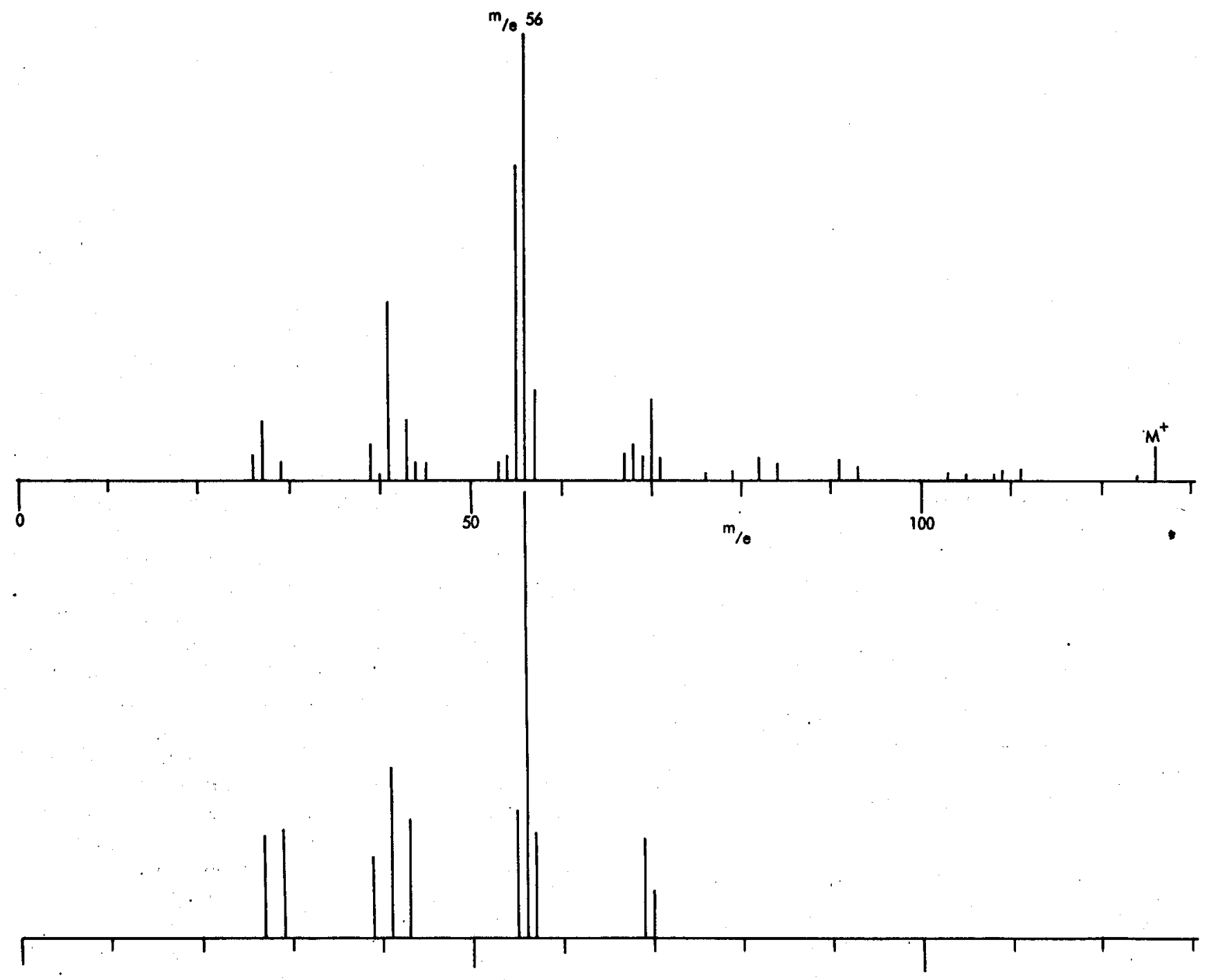

$\mathrm{C}_{2}-\mathrm{C}_{0}(19,21)$ and $\mathrm{C}_{10}-\mathrm{C}_{s 2}(17,19,21,28)$ ranges, but a rather puzzling absence of $\mathrm{C}_{7}-\mathrm{C}_{0}$ mono-olefins. We find that the mass spectrum (Figure 7 ) of peak 6 corresponds to a nonene, $\mathrm{C}_{9} \mathrm{H}_{18}$. The mass spectra of monoolefins with the double bond in different positions are generally very similar (29), because the activation energies for re-arrangement processes in ions are small compared with neutral molecules (30). Nevertheless, olefin isomers are not necessarily indistinguishable, and the spectrum of peak 6 closely resembles that of 2-methyl-1-octene with a strong $\mathrm{C}_{4} \mathrm{H}_{8}{ }^{+}$ion peak at m/e 56 .

\section{SUMMARY}

The gas phase of fresh tobacco smoke was injected onto an open-tubular gas chromatography column at low temperature. Mass spectra and retention data for components eluted on temperature programming suggest the presence of six new compounds: 1,1-, 1,2- cis-, and 1,2-trans-dimethylcyclopropanes; 1-chloro-5-methylhexane; 1,3,5-hexatriene; and 2-methyl-1-octene.

\section{ZUSAMMENFASSUNG}

Die Gasphase aus nativem Tabakrauch wurde bei niedriger Temperatur auf eine Kapillarsäule gegeben. Massenspektren und Retentionsdaten von Komponenten, die bei Anwendung eines Temperaturprogramms eluiert wurden, deuten auf die Anwesenheit von sechs neuen Verbindungen hin: 1.1-, 1.2-cis- und 1.2-trans-Dimethylcyclopropan; 1-Chlor-5-methylhexan; 1.3.5-Hexatrien und 2-Methylokten-1.

\section{RESUME}

Dans une colonne chromatographique ouverte à basse température, on a injecté la phase gazeuse de fumées fraîches de tabac. Ses spectres de masse ainsi que les temps de rétention à température programmée suggèrent la présence de six nouveaux composés: 1.1-, 1.2-ciset 1.2-trans-diméthylcyclopropanes; 1-chloro-5-méthylhexane; 1.3.5-hexatriène; et 2-méthyl-1-octène. 


\section{REFERENCES}

1. Grob, K.: J. Gas Chromatography 3 (1965) 52.

2. Grob, K.: Beitr. Tabakforsch. 3 (1965) 243.

3. Bartle, K. D., Bergstedt, L., Novotný, M., and Widmark, G.: J. Chromatog. 45 (1969) 256.

4. Novotný, M.: Chromatographia 2 (1969) 350.

5. Bergstedt, L., and Widmark, G.: Chromatographia 2 (1969) 529..

6. Cornu, A., and Massot, R.: "Compilation of mass spectral data", Heyden, London, 1966.

7. Newsome, J. R., Norman, V., and Keith, C. H.: Tob. Sci. 9 (1965) 102.

8. Caroff, J., Vernon, J., Badre, R., and Guillerm, R.: J. Gas Chromatography 3 (1965) 196.

9. Norman, V., Newsome, J. R., and Keith, C. H.: Div. Agric. Food Chem. ACS, New York, 1963; 17th Tob. Chem. Res. Conf., Montreal, 1963.

10. Phillipe, R. J., Moore, H., Honeycutt, R. G., and Ruth, J. M.: Anal. Chem. 36 (1964) 859.

11. Spears, A. W., and Routh, W. E.: 18th Tob. Chem. Res. Conf., Raleigh, 1964.

12. Phillipe, R. J., Honeycutt, R. G., and Ruth, J. M.: J. Chromatog. 20 (I965) 250.

13. Grob, K.: Beitr. Tabakforsch. 1 (1962) 315.

14. Grob, K.: 3rd Int. Sci. Tob. Congress, Salisbury, 1963.

15. Budziekiewicz, H., Djerassi, C., and Williams, D. H.: "Mass spectrometry of organic compounds", Holden-Day, San Francisco, 1967, p. 60.

16. Beynon, J. H., Saunders, R. A., and Williams, A. E.: "The mass spectra of organic molecules", Elsevier, Amsterdam, 1968, p. 108.

17. Grob, K.: Beitr. Tabakforsch. 3 (1966) 403.

18. Johnstone, R. A. W., and Plimmer, J. R.: Chem. Rev. 59 (1959) 885.

19. Elmenhorst, H., and Schultz, Ch.: Beitr. Tabakforsch. 4 (1968) go.
20. Guthrie, F. E., and Bowery, T. G.: Residue Rev. 19 (1967) 31.

21. Stedman, R. L.: Chem. Rev, 68 (1968) 153.

22. McLafferty, F. W.: Anal. Chem. 34 (1962) 2.

23. Ref. 15, p. 434 .

24. Völlmin, J. A., Omura, I., Seibl, J., Grob, K., and Simon, W.: Helv. Chim. Acta 49 (1966) 1768.

25. "Faraday encyclopaedia of hydrocarbon compounds", Butterworths, London, 1956.

26. Harris, G.: "Dictionary of organic compounds", Eyre and Spottiswoode, London, 1965.

27. Howton, D. R. : J. Org. Chem. 14 (1949) 1.

28. Entwistle, I. D., and Johnstone, R. A. W.: Chem. Ind. $1965,269$.

29. Beynon, J. H.: "Mass spectrometry and its application to organic chemistry", Elsevier, Amsterdam, 1960, p. 325.

30. Field, F. H., and Franklin, J. L.: "Electron impact phenomena", Academic Press, New York, 1957.

31. Avrahami, M., and Kebarle, P.: J. Phys. Chem. 67 (1963) 354 .

32. Kebarle, P., and Avrahami, M.: J. Chem. Phys. 38 (1963) 700 .

\section{Acknowledgements}

We thank the University of Stockholm, Sweden, for facilities, and the Swedish and Scandinavian Tobacco Companies for support. We are also grateful to $\mathrm{Mr}$. L. Bergstedt for recording the mass spectra.

Authors' addresses:

School of Chemistry, The University, Leeds, LS2 gJT, England.

Chemistry Department, University of Houston, Houston, Texas, 77004, USA. 